\title{
The incidence and magnitude of the health costs of in-person schooling during the COVID-19 pandemic
}

\author{
Casey B. Mulligan ${ }^{1}[0$
}

Received: 15 May 2021 / Accepted: 29 June 2021 / Published online: 24 July 2021

(C) The Author(s), under exclusive licence to Springer Science+Business Media, LLC, part of Springer Nature 2021

\begin{abstract}
The health costs of in-person schooling during the pandemic, if any, fall primarily on the families of students, largely owing to the fact that students significantly outnumber teachers. Data from North Carolina, Wisconsin, Australia, England, and Israel covering almost 80 million person-days in school during 2020 help assess the magnitude of the fatality risks of in-person schooling, accounting for mitigation protocols as well as the age and living arrangements of students and teachers. The risks of in-person schooling to unvaccinated teachers are, for those not yet elderly, small enough to challenge comprehension. Valued at a VSL of $\$ 10$ million, the average daily fatality cost ranges from $\$ 0.01$ for a young teacher living alone to as much as $\$ 29$ for an elderly teacher living with an elderly spouse. For each 22 million unvaccinated students and teachers schooling in-person for a 5-day week during the pandemic, the expected number of fatalities among teachers and their spouses is one or less.
\end{abstract}

Keywords Pandemic $\cdot$ Occupational risk · Compensating differences · Incidence of regulation $\cdot$ Externalities

JEL Classification D62 $\cdot$ I18 $\cdot$ J45

\section{Introduction}

The spread of COVID-19 in the United States has prompted extraordinary, although often untested, steps by individuals and institutions to limit infections. One of the longest-duration avoidance strategies has been the closing of public-school buildings even to uninfected students and teachers. Some have worried that part of "the cure is worse than the disease". The purpose of the present paper is to assess the incidence and magnitude of the private health benefits (if any) of remote learning or, conversely, the health costs of in-person schooling before a vaccine became available.

Because infectious respiratory diseases spread from person to person, in-person school is concerning because of the large number of personal contacts made there (Mossong et al.,

Casey B. Mulligan

c-mulligan@uchicago.edu

1 Kenneth C. Griffin Department of Economics, University of Chicago, Chicago, USA 
2008). In-person schooling appears to have contributed to the spread of previous seasonal flus (Cauchemez et al., 2008). However, prevention efforts are expected to be different during (and perhaps also following) a more dangerous pandemic such as COVID-19 (Philipson, 2000), especially in an organization where transmission can occur among fellow members (Leeson \& Rouanet, 2021; Mulligan, 2021b). We already know that in-person schools took many extra precautions during COVID-19 that often were absent in the wider community and were absent during flu seasons. ${ }^{1}$ Because prevention efforts potentially could reduce infection risks in schools both absolutely and relative to wider-community risks, additional measurement is required to assess the equilibrium infection rate a person could expect from participating in person at school and whether it is sufficient to justify the childdevelopment, family, and psychological costs of remote learning (Alon et al., 2021; Maldonado \& De Witte, 2020; Mulligan, 2021a; Wang et al., 2021).

The economics toolkit is essential for answering questions about disease spread. Human behavior both affects disease transmission and responds to incentives and economic organization. Economists have long analyzed and prepared standardized measures of occupational risks, of which contracting COVID-19 at school is a novel instance. This paper applies tools from the economics of compensating wage differentials, particularly in emphasizing the time dimension of infection risks (U.S. Bureau of Labor Statistics, 2010) and thereby their relationship with other health risks experienced in more familiar occupational and consumer settings. The same perspective also provides a new and useful accounting framework that relates metrics common in epidemiology to economic concepts such as incidence, externalities and marginal costs that are relevant for private and public choices.

This paper first addresses incidence questions, because their answers require the least information. There is little debate as to the pupil-teacher ratio, the age profile of fatality risks of COVID infections, or the distribution of age and living arrangements among teachers and parents of students. Although such demographic data by themselves are not enough to assess the magnitude of the risk of in-person teaching, they say a lot as to how the risk would be distributed across families. Sections 2 and 3 show that, in relative terms, the fatalities among the adults in student families from school-acquired COVID-19 would far outnumber those among teachers and spouses.

Section 4 of the paper shifts from relative risk toward the absolute level of risk of infection and death from school-acquired COVID-19. I assume that infection rates cannot be negative for students and teachers engaged in remote learning or whatever else may be their next-best alternative to in-person schooling during school hours. That assumption, together with data on the source of infections experienced by students and staff, allows for estimation of an upper bound on the effect of in-person schooling on infections and thereby fatalities. The rate that infections were acquired at K-12 school before a vaccine was available is estimated from a study of all open schools in England (Ismail et al., 2020), a study of Wisconsin schools (Falk et al., 2021) and a study of North Carolina schools (Zimmerman et al., 2021). COVID-19 prevalence in the surrounding communities varies by two orders of magnitude across the studies, with the propensity to acquire the infection in school varying nearly proportionally. Because no outbreak severe enough to close schools occurred

\footnotetext{
1 The precautions usually included face masks, restricted school entry, extra spacing, cohort arrangements, reduced class sizes, daily symptom screening, and cancellation of extracurricular activities (Lessler et al., 2021). See also Oster et al. (2021) and van den Berg et al. (2021).
} 
during the three studies, I supplement them with Israeli data where a COVID outbreak did occur in a school (Stein-Zamir et al., 2020).

The infection-rate findings in combination with the incidence findings suggest that the upper bound for fatality risks from unvaccinated in-person schooling varies by age and living arrangements. As long as community prevalence and school prevention protocols are in the range that occurred during fall 2020 in the various US states, those risks are similar to the fatality risks of commuting by automobile (Sect. 5). For each 22 million unvaccinated students and teachers schooling in-person for a 5-day week, the expected number of fatalities among teachers and spouses is one or less. Note that 22 million people distanced six feet apart would form a line that covers the entire Earth's equator and overlap itself again for 2700 miles.

An "Appendix" reviews a study of New South Wales, Australia, estimating in-school "secondary attack rates": the number of infections among in-school close contacts of infectious persons who were present in school. Arguably, the estimated attack rates in Australia and elsewhere are in line with the three aforementioned studies of sources of infection. The results suggest that infections rarely are acquired in school because of a combination of low attack rates and school successes at keeping community members out of the school while they are infectious.

The paper focuses on infections experienced by students, teachers, and their immediate family members. It does not attempt to estimate community, national, or world-level health effects that occur as students and teachers and their family members go out into the broader community. Courtemanche et al. (2021) find that COVID-19 cases and deaths increase in early-school-opening Texas counties relative to the others, although the same quantitative relationship also is apparent in the weeks preceding the actual school opening. ${ }^{2}$

\section{Incidence arithmetic}

Private health costs (or, possibly, benefits) of in-person schooling accrue to teachers, students, and each of their families. ${ }^{3}$ A bit of arithmetic shows how the share of the total health costs accruing to students and their families can be estimated with fewer data and assumptions than are required to estimate the overall level of health costs. Conceptually, I distinguish fatality costs from the nonfatal health costs of COVID-19, such as chronic conditions or injuries. The fatality costs of each group are decomposed into the product of the number of cases the group acquires at school and the group's average infection fatality rate. The health costs similarly can be decomposed into the number of infections and an infection nonfatal-injury rate. For family members who are not present at school, cases acquired "at school" are the product of cases acquired by the student (or teacher) in their household times the household transmission rate (HHT) for COVID-19. Individuals who share a household with multiple students or a teacher and student are counted multiple times, once

\footnotetext{
2 Moreover, the authors cite three other studies (Goldhaber et al., 2021; Harris et al., 2021; Isphording et al., 2020) looking at community prevalence, which they characterize as "find[ing] little evidence that reopening schools increases COVID-19 spread on average.".

3 Non-teaching staff also would bear some of the burden to the extent that they are present with students or teachers during in-person schooling. Before the pandemic, $73 \%$ of the staff in public primary and secondary schools were teachers (National Center for Education Statistics, 2020, Table 213.10).
} 
for each household member present at school. ${ }^{4}$ As is appropriate for assessing private costs of in-person schooling, this paper does not estimate infection risk for the broader community of such households. Broader-community effects would be necessary for social-welfare calculations.

Assume for the moment that (1) the adults involved have the same (nonzero) fatalities per infection $\left(I F R_{\text {adult }}\right)$ regardless of whether associated with student or teacher, (2) inschool infections per teacher are no greater than in-school infections per student, and (3) each household has exactly two adults. The fatalities per student infection are therefore $I F R_{\text {student }}+2$ HHT IFR adult, where the factor of two represents both adults in the student household. Fatalities per teacher infection are $(1+H H T) I F R_{\text {adult }}$. Inequality (1) therefore is a sufficient condition for aggregate student-family fatalities from COVID acquired in school to exceed those for teacher-family fatalities.

$$
\left(2 \frac{\text { students }}{\text { teachers }}-1\right) H H T+\frac{\text { students }}{\text { teachers }} \frac{I F R_{\text {student }}}{I F R_{\text {adult }}}>1
$$

IFR denotes the average number of fatalities per COVID infection, which would be replaced by the injury rate for the purposes of deriving an inequality for nonfatal injuries. Note that the number of infections acquired in school is absent from (1). That number affects the overall level of fatalities among teacher and student families, but not the comparison of the two. Inequality (1) requires only the relative infection fatality rate and, especially, the student-teacher ratio.

The RHS of (1) represents the fatalities of teachers, as distinct from their spouses. The $H H T$ term on the LHS represents family members of students (before the minus sign) and of teachers (after the minus sign). The two is present because all adults in a two-adult student household are outside the school but only one of the adults in a two-adult teacher household are outside the school. The second term on the LHS is the ratio of student fatalities to teacher fatalities. Either of the two LHS terms exceeding one would be sufficient to satisfy (1).

Assumptions (i)-(iii) are relaxed in subsequent empirical estimates, but are made here to highlight the major determinants of the incidence results. Especially with many students per teacher, inequality (1) reveals why student families likely bear most of the private health costs of in-person schooling. Take a student-teacher ratio of 15 . Any $H H T$ greater than $1 / 29$ is, according to (1), sufficient to conclude that in-person schooling would generate more fatalities for student families than teacher families. If the number of adults in the household sometimes differs from two, then the HHT coefficient becomes $A_{\text {student }} \frac{\text { students }}{\text { teachers }}-A_{\text {teacher }}+1$, where $A$ indicates the average number of adults in each type of household. As shown in the next section, empirical values for the As are not different enough from two to significantly modify the 1/29 cutoff for $H H T$.

\footnotetext{
${ }^{4}$ Such sharing overstates the individual's risk because acquiring infection from one family member may avoid being infected by a second family member. However, given the low in-school infection rates, the overstatement is miniscule.
} 


\section{Demographic data used in this paper}

To estimate the distribution of fatalities between student and teacher families without relying on assumptions (i)-(iii), I draw on four sources. As suggested by inspection of inequality (1), the most important variable is the pupil-teacher ratio of 15.4 from the National Center for Education Statistics (2020, Table 208.20). Second is the distribution of ages and living arrangements for teachers, students, and their families, which I take from the January through March 2020 Current Population Surveys (CPS) as provided by IPUMS. ${ }^{5}$ Students are identified as any child age 6-15 plus any person aged 16-24 who reports full-time highschool enrollment. Teachers are identified as any person with a job during the survey week and occupation code for teachers of preschool, kindergarten, elementary, middle, or high school. ${ }^{6}$ That definition relaxes assumption (iii). Third, I rely on Grijalva et al.'s (2020) estimates of the household transmission rate of COVID infections. They estimate that, conditional on having an infection in the household, 59\% of household members aged 18-49 were infected on average (including asymptomatic cases as infections). They estimate $43 \%$ for ages 50 and older. ${ }^{7}$ Fourth, relaxing assumption (i), I take age-specific infection-fatality rates, for unvaccinated persons, from Yang et al. (2021). ${ }^{8}$ The mean and median case fatality rates are $0.79 \%$ and $0.12 \%$ for the adults in teacher families, respectively. For the adults in student families, the corresponding rates are $0.59 \%$ and $0.12 \%$.

Because in-school transmissions proved to be rare, and teachers are significantly outnumbered by students, it is difficult to know whether hourly infection rates are different for students and teachers. Some of the studies report results only for students and staffed pooled. ${ }^{9}$ I henceforth assume that in-person students and staff have the same hourly infection rates.

The first numerical column of Table 1 shows the results using only the aforementioned HHT estimates, age-specific infection fatality rates, and pre-pandemic demographic data. Assuming that students and teachers are unvaccinated and present in-person in the normal 15.4 ratio, Table 1 shows that $88 \%$ of the fatalities from infections acquired in school or from an immediate family member who was in school would occur in the families of the students. Student households with two adults aged 45-64 would experience 28.1 percentage points of the 88 because that living arrangement is common, and the adults have above-average fatality risk. They represent $19 \%$ of student households, and thereby $18 \%$ $(=19 *[15.4 /(1+15.4)])$ of all households with a person in school. Each adult in that household type has a $0.4 \%$ fatality rate conditional on a student infection, which sum to

\footnotetext{
5 The CPS is conducted on the week including the 12th of the month. In 2020, the week of March 12 was the week before most schools closed during the pandemic.

6 By these definitions, the national total of CPS students per CPS teacher is only 9.9, in part because not all persons indicated as teachers in the CPS are in the classroom every day. The total CPS students by this definition is 51.6 million, as compared to 56.4 million elementary and secondary school students reported by NCES.

7 Although it is not the focus of their study, Vlachos et al (2021) estimate a secondary attack rate of 52\% specifically from Swedish teachers to their spouses. Cutting the assumed household transmission rates in half reduces my estimates of teacher-family fatality risk (Table 6) by $13 \%$.

8 Yang et al. (2021, p. 206) "estimated an overall infection-fatality risk of $1.39 \%$ ", ranging from $0.00972 \%$ for under age 25 to $14.2 \%$ for age 75 and over.

${ }^{9}$ For what it is worth, no study of the fall 2020 term reports more in-school infections among staff than among students.
} 


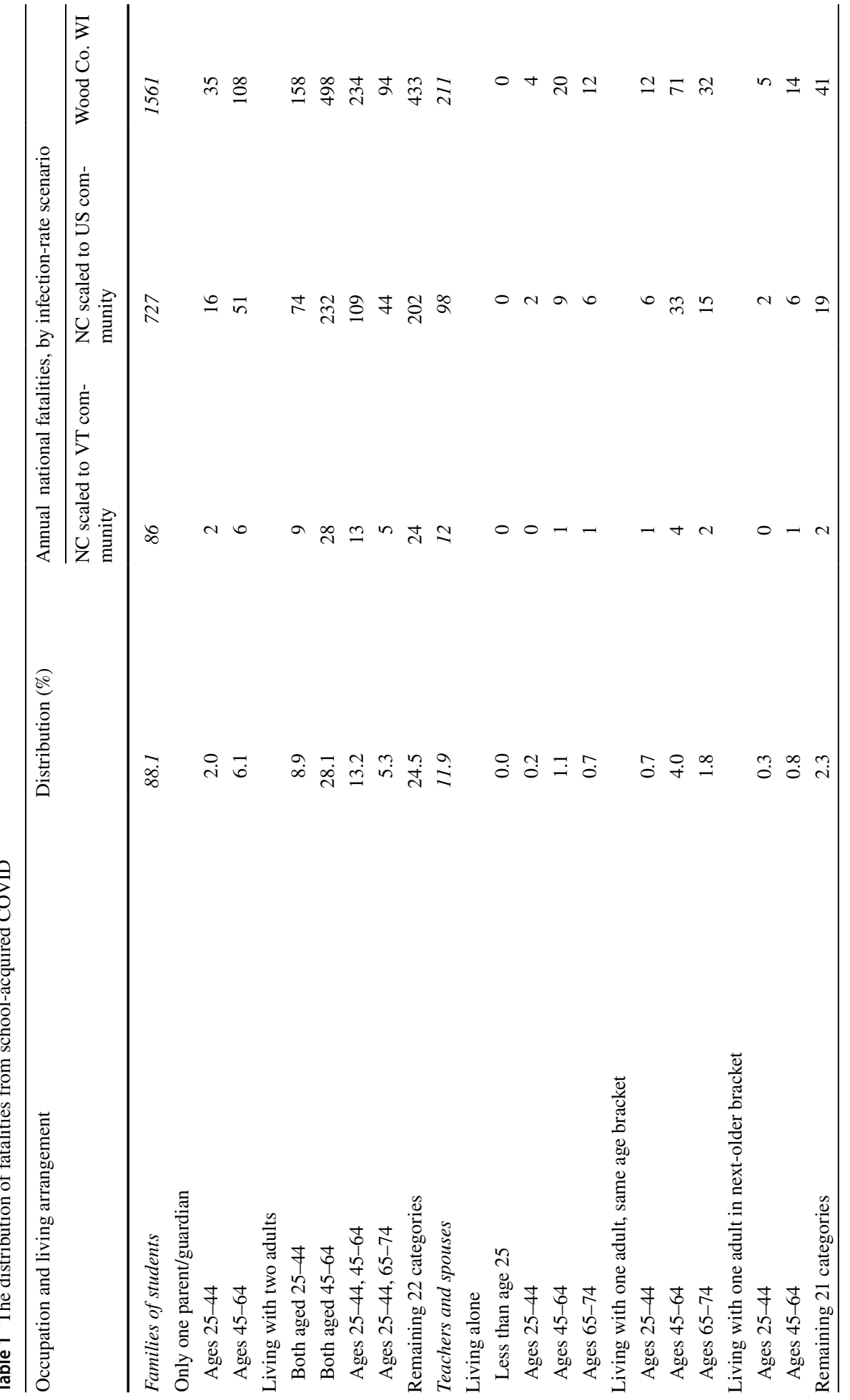




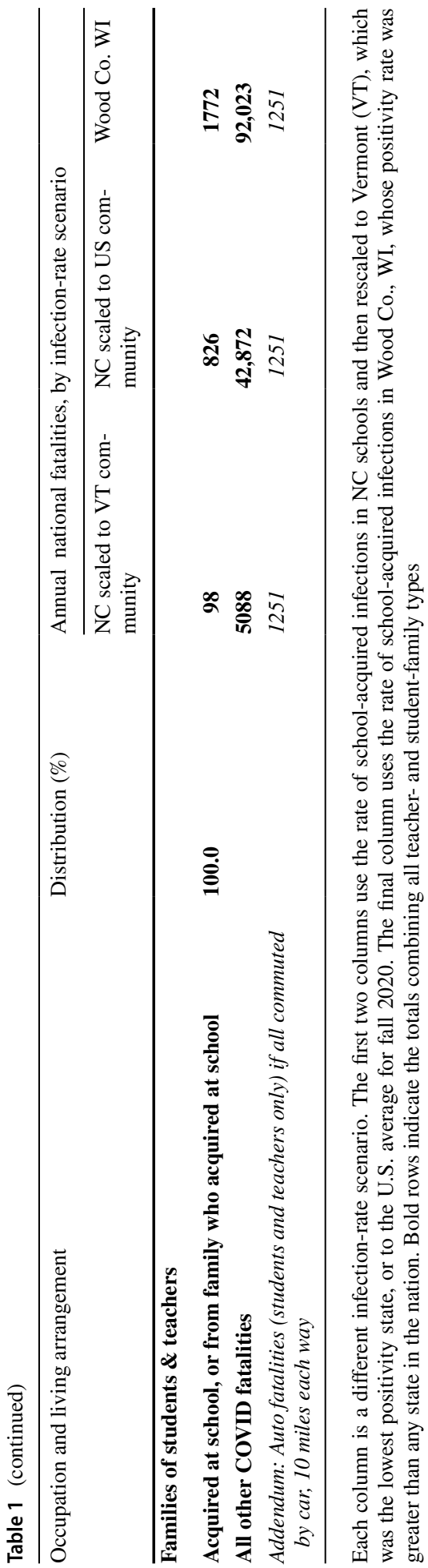


$0.8 \%$ for the household, as compared to $0.5 \%$ for the average household. Up to rounding error, the $28 \%$ shown in the table is $18 *(0.8 / 0.5)$.

Only $12 \%$ of the fatalities would be teachers or their spouses. If non-fatal injury risks are proportional to fatalities, then the distribution shown in the first column also is a distribution of the non-fatal COVID-19 injuries originating in schools. Using an alternative student-teacher ratio would reallocate between the $88 \%$ and $12 \%$ accordingly.

\section{School transmission data}

Three types of studies have measured the relationship between schooling and COVID-19 infections. Two of them measure infections among students, teachers, or other staff who actually were present at a school during the pandemic. One of those two, emphasized in this paper, attempts to measure the source of infection as a contact made at school versus a contact made elsewhere in the community. The second type, also used in this paper, lacks information on infection source but compares prevalence to other groups of people who were not present at a school. Both of those study types can, with additional assumptions, help estimate the maximum infection students and staff might have avoided if they had instead been absent in school.

In practice, the two types of studies typically do not assess how the wider community is affected by the activities of students and staff. Wider community effects may have little relevance for the private costs and benefits of location decisions by students and staff, but they are relevant for estimating the social costs and benefits (Courtemanche et al., 2021). This third type of study is beyond the scope of this paper.

\subsection{The frequency of in-school transmission}

Additional data, discussed further below, are required to obtain estimates of the expected number of fatalities such as those shown in the final three columns of Table 1. Estimating the level of fatality risks from in-person schooling is the purpose of the remainder of the present paper. It requires estimates of the number of cases acquired in school and the number of cases acquired by remote learners during school hours, or at least estimates of the difference between the two. As a bounding exercise, I assume that zero cases are acquired by remote learners during school hours and then return to that assumption at the end of the paper.

Although this paper does not have access to original infection data, it does assemble published data from five distinct settings and puts their findings in common metrics. The metrics are selected for comparability with familiar risks and with metrics used in the literature on occupational safety and compensating differentials. Sometimes computation of the common metrics requires supplementing the published data with additional schooling data from the same setting of the published study. ${ }^{10}$ In particular, the metrics account for the "duration of exposure" (U.S. Bureau of Labor Statistics, 2010), which for students and teachers is the amount of time they are present at school. The time dimension of risks, usually absent from epidemiology articles, is particularly relevant for private and public

${ }^{10}$ For example, one study reports only median attendance rather than mean attendance. 
choices because the tradeoff between in-person and remote learning is a question of time allocation.

I found five published studies on school-acquired cases, one from Australia; England; North Carolina; Wood County, Wisconsin; and an Israeli school that experienced an outbreak. ${ }^{11}$ The Australian study examines only the (rare) classrooms into which a student or staff entered with an infection during the study period, thus providing an "attack rate" rather than a rate of infection that accounts for the fact that on some days none of a person's contacts at school would be infected. The similarities and differences between attack and infection rates are discussed further in the "Appendix" to this paper.

Ismail et al. (2020) looked at the entire country of England between June 1 and July 17, 2020, which is the summer half term as England "reopened after the first national lockdown". For comparability with the other studies, I use their results for primary and secondary schools and supplement with attendance data from the UK Department for Education and prevalence data from Our World in Data. Most of the schools were open at some point during that time and the majority of staff appear to have been present. However, summer-term attendance was not mandatory and therefore student attendance overall was only about one-sixth of what it would be later in the fall and even less in secondary schools (Ismail et al., 2020; U.K. Office of Statistics Regulation, 2020). The types of students attending during the UK may be different from those attending during the fall term. Overall, 32 million staff days present and 43 million student days present in about 20,000 schools were covered by the study.

"Extensive social distancing and infection control measures were implemented with strict limitations on the number of staff and children in each bubble" (Ismail et al., 2020, p. 352). Ninety-six staff and eight student cases were identified by Public Health England (PHE) as potentially acquired in primary and secondary schools, although the study did not always verify that the person acquiring infection was ever in close contact with the primary case. ${ }^{12}$ That is about 721,000 person-days per infection. Reweighting the student and staff infection rate to reflect the 15.4 teacher-pupil ratio that is normal during the academic year, that is 2.8 million person-days per infection. Taking an academic year as 180 days, that is 15,561 person-years per infection as shown in the first row of Table 2. New cases were low in England during that time; rescaling to the per capita new infections in the United States during its fall 2020 term yields about 707 person-years per school-acquired infection. ${ }^{13}$

Note that all data in this subsection refer to COVID-19 infections rather than COVID-19 deaths, which are two orders of magnitude less common. The probabilities and rates being measured in Table 2 and following are very small and therefore not measured with high

\footnotetext{
11 The English study (Ismail et al., 2020) refers to all in-school transmission as "outbreak". This paper refers to an outbreak as enough transmissions in a single school over a short time horizon that the school was closed.

12 The study acknowledges that persons in the same school sometimes interact outside of school. The study also notes that only one teacher in England died from COVID during this period, which was acquired from a spouse who acquired it in the community. Regarding the information available for monitoring transmission, the authors note that "PHE has legal permission ... to process patient confidential information for national surveillance of communicable diseases and as such, individual patient consent is not required.".

13 Whenever rescaling is performed in this paper, it takes the inverse school-acquired infection rate from the study, multiplies by the positivity rate for the locality where the study occurred, and divides by the positivity rate for the U.S. (or other area such as Vermont, as specified by the infection scenario). The result is the rescaled inverse school-acquired infection rate. As noted in the tables, case rates are used for England rather than positivity rates. Also note that both inverse-infection entries in Table 2 for England have been reweighted to reflect a 15.4 pupil-teacher ratio rather than the ratio of 1.3 that prevailed during the study.
} 
Table 2 Person years at school per school-acquired infection: Four sources

\begin{tabular}{|c|c|c|c|}
\hline \multirow[t]{2}{*}{ Setting } & \multirow[t]{2}{*}{ Person-years } & \multicolumn{2}{|c|}{ Person-years per infection } \\
\hline & & Measured & $\begin{array}{l}\text { Adj. to U.S. positivity } \\
\text { September 1-November } \\
29\end{array}$ \\
\hline England: entire nation June 1-July 17 & 416,793 & 15,561 & 707 \\
\hline NC: 11 school districts August 15-October 23 & 12,732 & 398 & 377 \\
\hline WI: 17 schools August 31-November 29 & 1229 & 176 & 549 \\
\hline Addendum: Australian attack-rate study & N/A & N/A & 250 \\
\hline
\end{tabular}

The adjustment to U.S. is a ratio of CDC-published positivity rates for the corresponding location and time period. The exception is England, where the ratio of new cases per capita is used. See also the "Appendix" on attack rates. A person-year at school is 180 person days at school

precision. The 15,561 person-years per infection (the inverse of a daily infection rate) can hardly be distinguished from 15,000, let alone from 15,562.

About half of the North Carolina's school districts participated in some capacity in the study by Zimmerman et al. (2021). The participants were somewhat larger school districts with somewhat less in-person instruction than average. Many of the participating districts did not offer any in-person instruction and therefore did not provide any data for analysis herein. The authors explain how "districts were required to have universal masking for all $\geq 5$ years of age (except the adapted curriculum, during meals, and when sufficiently distanced outside), implement 6-foot distancing, and wash hands ... as well as perform daily symptom monitoring and temperature checks", adding that "case adjudication of within-school transmission was performed via contact tracing by the local health department." None of the schools offering in-person instruction had to terminate the instruction during the study period because of an outbreak or any other factor.

The study shows 90,338 in-person students and staff in the 11 districts providing inschool data over the 9 weeks of the study, which makes for a maximum of four million person-days. The study notes that somewhat more than 3000 persons quarantined at home at some point during the study, which I take to be 31,000 person-days out of the potential number. ${ }^{14}$ Because many students were on hybrid schedules, I assume that half of the potential in-person days were spent off campus on scheduled remote learning, putting my estimate of in-person days at about 2.3 million, which is 12,732 person-years. With 32 cases acquired in school from August 15 through October 23, 2020, the inverse of the infection rate is about 398 person-years. ${ }^{15}$ According to the COVID-testing data from the US Department of Health and Human Services (2021), the state of North Carolina's positivity rate during its study was slightly less than the nationwide average rate for the full fall term. The final column of Table 2 therefore shows an inverse rate of about 377 when adjusted to US positivity rates.

The Wood County, Wisconsin study (Falk et al., 2021) involved about 5600 students and staff attending in person for at least part of the week. In-person elementary students

\footnotetext{
14 All close contacts were quarantined for 14 days.

15 In principle, asymptomatic secondary cases would be included among the 32 because testing of contacts "was encouraged by NCDHHS, but not required" (Zimmerman et al., 2021).
} 
attended every day. Middle and high school students attended half-days on average across the nine such schools in the study. ${ }^{16}$ Mask wearing was required, students were organized in classroom cohorts of size 11-20, all classes and lunch periods were held indoors, and close contacts of positives were quarantined. I assume that quarantine days are the same percentage of the calendar as in North Carolina, except rescaled for the higher positivity rate in Wood County.

The study lasted 13 weeks (August 31-November 29), during which time typically seven holidays/teacher-workshops occurred, putting total time in person at about 1229 person-years. Seven cases were acquired in school during that time, putting the inverse infection rate at about 176 person-years. The average positivity rate in Wood County at that time exceeded even that of the highest US state rate (Montana) and was triple the US average. The final column therefore shows an adjusted inverse infection rate of about 549 person-years.

Table 2 reveals that surrounding-community COVID prevalence varies almost two orders of magnitude across studies. Although uniformly low by standards discussed further in the next section, the measured rates of school-acquired infection vary across the studies in close proportion to the surrounding-community prevalence, explaining why the final column of Table 2 varies much less than the second column. Ismail et al.'s (2020) study of England is large enough to investigate the proportionality hypothesis within their own study; they confirm that a region's school-acquired infection rate is nearly proportional to its overall prevalence.

Estimating separate infection rates for students and staff is difficult because of the small numbers of transmissions in the North Carolina and Wisconsin studies. For what it is worth, the Wisconsin study found zero staff cases acquired in school. Of the 32 cases of in-school transmission found in the North Carolina study, none were student-to-staff. Most of the cases found in the English study were among staff, but the staff-pupil ratio was particularly high during the time of the study (summer break).

All of these studies raise concerns that cases are underestimated. However, under the weak assumption that true cumulative COVID-19 infections cannot exceed the population, cases generally are not undercounted by more than a factor of ten. ${ }^{17}$ Furthermore, Sect. 5 below multiplies cases per capita by fatalities per case, which means that any proportional case measurement error that is common to the two sources will cancel for the purposes of assessing fatalities per capita. ${ }^{18}$ The "Appendix"'s attack rate estimates also are interesting in that regard because the attack rate is a ratio of cases to cases. Even if Sect. 2's fatalityrate estimates were multiplied by ten because of suspected undercounts, the rates would still be in the range of familiar risks.

None of the studies directly report person-days present in person, which is the denominator for my transmission rates. As described above, I have estimated based on information provided in the published articles together with supplemental information I found online. My point estimates of person-days per school-acquired infection (and thereby the estimates

\footnotetext{
16 Scheduled in-person days per week were measured from school district websites (Pittsville School District, 2020; Port Edwards School District, 2020a, b; School District of Auburndale, 2020; School District of Marshfield, 2020; School District of Nekoosa, 2020).

17 At the time of my writing, cumulative US cases represented $9 \%$ of the population, with new cases added at a rate of about 50,000 per day.

${ }^{18}$ For the purposes of estimating fatalities with the Yang et al. (2021) parameters, the distinction between deaths per infection and deaths per confirmed case is minor because Yang et al. find 1.4\% for the former whereas, through mid 2021; Centers for Disease Control and Prevention (2021) finds $1.8 \%$ for the latter.
} 
of person-years per school-acquired fatality that follow) can be understood as over- or underestimates in the same proportion that I over- or underestimated in-person attendance, respectively.

The North Carolina and Wisconsin studies measured community-acquired cases among their students and staff as well as school-acquired infections. Table 3 shows the corresponding (inverse) annualized infection rates for the student and teacher populations regardless of whether acquired in school or not. For that purpose, days outside of school are added to the person-years numerator from Table 2 and community-acquired cases added to the denominator; a year in Table 3 is 365 days rather than 180. The final column rescales the results to the US average positivity rate. The person years shown in Table 3 are about onetenth those shown in Table 2 because (1) the North Carolina and Wisconsin studies found that the daily rate of acquiring a COVID-19 infection in school is, for students and staff, about one-twentieth of the rate of acquiring an infection from any source and (2) about half of calendar days are spent outside of school (weekends, and so on). ${ }^{19}$

\subsection{Relative prevalence among people present at school}

Emily Oster (2020a, b) has led a "COVID-19 School Response Dashboard" project gathering attendance and prevalence data from participating schools in almost every US state. The prevalence measures are only for school students and staff, but do not distinguish infections acquired in school from those acquired at home or in the community. Table 3 therefore provides the appropriate comparison. Oster's data show about 38 person-years per infection (i.e., an annual infection rate of about 1/38). The Wisconsin study finds a higher infection rate in a high-positivity area, which corresponds to a rescaled annual infection rate of about 1/46. The rescaled rate in the North Carolina study (Zimmerman et al., 2021) is about $1 / 37$.

The Centers for Disease Control and Prevention (CDC) provides national case counts by age group, with the population-weighted sum across age groups yielding the national case counts. The CDC data can be reweighted to reflect the age of students, or the age of teachers, rather than the nation as a whole. The final rows of Table 3 show the results applied to the period September 1 through November 29, 2020. ${ }^{20}$ The four sources shown in the table reveal similar infection rates once they are rescaled by the prevalence in the communities where the data were collected.

Bravata et al. (2021) look at prevalence gaps between US household types using a continuous measure of school visits derived from mobility data. They find a small positive relationship between school visits and cases in households with children, which they acknowledge is not entirely causal. They find a coefficient of essentially the same magnitude-but the opposite sign-for cases in households with teachers.

Sweden is an interesting comparison to the United States because it appears to be in between US COVID-19 and US seasonal flu on the scale of prevention effort in schools. For example, in Sweden during COVID-19 close contacts were not required to quarantine,

\footnotetext{
19 For the purposes of Table 3, the daily rate includes weekends.

20 The CDC age distribution of cases, which it calculates cumulatively for most of the pandemic, is rescaled to match new national daily infections during fall 2020. Age-specific daily infection rates for the fall are found by dividing age-specific daily infections by the national population in that age group. The results shown in Table 3 are inverse weighted averages of the age-specific daily infection rates.
} 
Table 3 Person years per infection, including those acquired outside school

\begin{tabular}{lll}
\hline Setting & \multicolumn{2}{l}{ Person-years per infection } \\
\cline { 2 - 3 } & Measured & $\begin{array}{l}\text { Adj. to U.S. positivity } \\
\text { September 1-November } \\
29\end{array}$ \\
& & 37.2 \\
NC: 11 school districts August 15-October 23 & 39.3 & 45.8 \\
WI: 17 schools August 31-November 29 & 14.6 & \\
Oster/Covid School Dashboard August 31-November 22 & & 40.9 \\
Students & N/A & 18.8 \\
Staff & N/A & 37.5 \\
Combined at 11.7 student-staff ratio & N/A & \\
CDC prevalence data reweighted based on age of & & 31.3 \\
Students & & 15.2 \\
Teachers & & 28.9 \\
Combined at 11.7 student-staff ratio & & \\
\hline
\end{tabular}

Weekend days, holidays, quarantine days and (for hybrid learners) remote-learning days are counted in the numerator

class size did not have to be reduced, and face masks were not specifically recommended. ${ }^{21}$ Vlachos et al. (2021) conclude that parents of an in-school child are 17\% more likely, relative to parents of a remote learner, to have a positive polymerase chain reaction (PCR) test but $6 \%$ less likely to have a COVID diagnosis from a healthcare visit. Ludvigsson et al. (2021) find that teachers in Sweden had a relative risk of COVID-19 ICU admissions of 0.43 compared to a baseline of other non-healthcare occupations.

Arguably England, Wisconsin and North Carolina were "lucky" in that in-person school was not terminated during the study period owing to an outbreak. The present paper therefore additionally considers a hypothetical "high-risk" scenario in which Wood County (with its high community prevalence) experienced an outbreak, whose probability and intensity I measure from Israel as the number of infections in the Israeli school that had an outbreak divided by the nationwide number of student-days of in-person schooling that occurred between the opening of Israel's schools to the reclosing upon outbreak (SteinZamir et al., 2020). That approach likely exaggerates the probability and intensity of an outbreak in US schools because (1) Israel was selected because it had an outbreak, (2) all but two of the cases in the Israeli school are assumed to come from the outbreak rather than the broader community, and (3) the outbreak school was not requiring masks and other mitigation methods commonly adopted in schools. ${ }^{22}$

21 Vlachos et al. (2021). Moreover, "student absenteeism increased [during the pandemic], but not dramatically so." See also Ludvigsson et al. (2021), who observed that Sweden had "no enforced quarantines for infected households or geographic regions, and facemasks were not recommended outside health care.".

22 The study notes two index cases that came into the school from the community (Stein-Zamir et al., 2020). 


\subsection{Fatality benchmarks}

For comparison purposes, this paper also shows fatality risks in more familiar occupational and consumer contexts. The comparison of familiar risks with COVID-19 risks serves two purposes. One is to provide context given that a pandemic is a new experience for many people. Second, the comparisons show if the COVID-19 risks are in the range of risks that have been priced in labor and consumer markets (Viscusi, 1992; Viscusi \& Aldy, 2003).

Table 4's middle column shows fatality risks for selected pre-pandemic activities, sorted by fatality risk, from the National Census of Fatal Occupational Injuries published by the US Bureau of Labor Statistics (2020a, b). BLS measures the risks per year engaged in an occupation, not including fatalities experienced while commuting to work. The two riskiest occupations reported by BLS are "fishing and hunting workers" and loggers, which experience roughly 1000 person-years per fatality on the job. Farming has about 4000 person years per fatal injury on the job. Driving occupations-both truck drivers and sales workers-also average about 4000 person-years per fatality. Educational and health services industries, which include schools, were safer than the average $(28,571$ person-years per fatality) at 125,000 person-years per fatality.

On the consumer side, driving is a familiar fatality risk. Many adults, teachers included, commute to work daily by car. The US Department of Transportation $(2017,2020)$ measures automobile fatalities per mile traveled, which I convert to daily risks by selecting various commuting lengths. ${ }^{23}$ The purpose here is not to estimate the modes or numbers of miles that teachers and students commute but rather to provide information on risks familiar to adults generally. Therefore, Table 2's final column expresses the differences among occupations in terms of miles driven per day. For example, government workers normally experience less occupational risk than the average worker, but the combined occupational and commuting risk would be equal to the average if the government workers commuted 17 miles more per day than the average worker did.

Of particular interest is the final addendum row of the table. It combines pre-pandemic fatality risk for in-person teachers with the modal fall 2020 risk to self and spouse of death from school-acquired COVID-19, examined in more detail in the tables that follow. The combined risk for teachers (77,547 person-years per infection) is still less than even government workers generally experienced before the pandemic $(55,556)$. The impact of COVID on the risk to the modal teacher and spouse is the equivalent of driving approximately four $(=26-22)$ additional miles each workday.

All such activities also involve prevention and treatment costs to reduce fatalities. Vehicles are built with seatbelts and engineering features to help protect passengers. Drivers and the legal system limit speeds, drunk driving and constrain other highway risks. Many auto injuries are not fatal because of medical resources spent to help the victim survive. Pandemic risks also have those qualitative features, including personal protective equipment and various hospitalization treatments. Unlike COVID-19, many familiar workplace accidents are neither infectious nor contagious, although automobile accidents often do involve third parties who are on foot or in another vehicle.

The distinction between accident and fatality is relevant for decision making, especially because the fatalities are comparatively rare. A new traffic pattern can, in principle, be

\footnotetext{
${ }^{23}$ Because this paper focuses on primary and secondary schools, in which face-to-face student learning normally occurs 180 days per year, when necessary, I adopt a factor of 180 to convert between person years and person days. Both driver and passenger(s) count in the numerator for automobile fatalities.
} 
Table 4 Person years of selected activities per fatality in that activity

\begin{tabular}{lcc}
\hline circa 2019 & & \\
\hline Occupation or industry (sorted more fatal to less) & $\begin{array}{l}\text { Person-years } \\
\text { per fatality }\end{array}$ & $\begin{array}{l}\text { Additional daily commuting distance to } \\
\text { match average occupational mortality }\end{array}$ \\
\hline Fishing and hunting workers & 690 & -1385 \\
Loggers & 1451 & -640 \\
Aircraft pilots and flight engineers & 1618 & -571 \\
Driver/sales workers and truck drivers & 3731 & -228 \\
Farming & 4310 & -193 \\
Police & 7299 & -100 \\
Construction & 10,309 & -61 \\
All jobs & 28,571 & 0 \\
Government & 55,556 & 17 \\
Educational and health services & 125,000 & 26 \\
Professional and related occupations & 142,857 & 27 \\
Addendum & & \\
Fall 2020 modal in-person teacher & 77,547 & 22
\end{tabular}

Commuting days are converted to years using 180 days per year. The final column shows the additional daily miles that a participant in the activity would have to commute in order to have the same occupation plus commuting fatality risk as the average worker. The first two rows are the highest-fatality occupations reported by the Bureau of Labor Statistics. Addendum row uses "Education and health services" row as baseline risk and adds the modal teacher's COVID risk to self and spouse from Table 6

Occupational sources: U.S. Bureau of Labor Statistics (2020a, b, c, d)

Commuting sources: Savage (2013), U.S. Dept. of Transportation $(2017,2020)$

monitored for accidents and modified before a fatality occurs. ${ }^{24}$ With COVID-19, the infections are about 100 times more common than fatalities and the former can be monitored in a new schooling situation and adjusted before a fatality occurs.

Cases per fatality are expected to be greater in schools than all-adult workplaces because most of the people in school are children, who have low COVID mortality rates. In other words, schools would have a Bayesian advantage (from the perspective of preventing fatalities) over all-adult workplaces even if children were equally likely to transmit infections: cases among children serve as a warning to adults without posing the fatality risks of cases among adults. The Israeli outbreak was discovered in that way. Moreover, because being a student is a fairly homogeneous activity engaging tens of millions, schools can learn from each other faster than, say, a law office could learn from the accident results at a meatpacking factory. Although pandemics are not new, the learning rate is relevant because COVID19 is far newer than automobiles or farm equipment.

Table 5 quantifies some of the Bayesian elements of fatality risks by analogizing motorvehicle accidents to COVID infections, which is a way of reconciling infections (Tables 2, 3) with fatalities (Table 4). Motor vehicles have 345 reported accidents per motor vehicle fatality. COVID "accidents" - that is, cases - per fatality are of a similar order of

\footnotetext{
${ }^{24}$ According to the National Safety Council (2020), 345 motor-vehicle crashes occurred for every crashrelated fatality.
} 
Table 5 Reported accidents per fatality

\begin{tabular}{lr}
\hline Motor vehicles, 2019 & 345 \\
COVID, general population & 56 \\
COVID, school population & 196 \\
COVID, school population w/o elderly family & 285 \\
\hline
\end{tabular}

A confirmed COVID case is considered a "reported accident" for the purposes of this table

Sources: National Safety Council (2020), Johns Hopkins, Current Population Surveys January-March 2020, Yang et al. (2021)

magnitude. The general population experienced one COVID fatality per 56 cases. The school population had more cases per fatality - equivalently fewer fatalities per casebecause it is younger than the general population. The lowest of the three case fatality rates, and therefore the most COVID accidents per fatality at 285, is in the school population limited to exclude the elderly. This final entry in Table 5 is potentially relevant for policymaking because, perhaps in an initial phase in which a school is uncertain as to whether its prevention protocols are sufficiently effective, students and teachers who live with elderly people could be excused from in-person attendance.

\section{Private fatality risks accounting for age and living arrangements}

Table 6 combines the results in Tables 1 and 2 to show fatality risks for unvaccinated teachers and their unvaccinated spouses. The rows of the table are age and living-arrangement cells, ranging from the most common (couples aged 25-44) to the least common (elderly teacher living alone). The percentages in the first numerical column sum to $100 \%$. The second column shows the expected number of fatalities that result for the household's adults if the teacher brings home an infection from school. For teachers living without any other adult, it is simply the infection fatality rate (IFR) for persons of their age. ${ }^{25}$ For teachers living with another adult, the second column takes the household transmission rate times the IFR corresponding to the age of the spouse/partner and adds the IFR for the teacher. The remaining four columns show (inverse) fatality rates for various in-school COVID transmission scenarios. Each inverse fatality rate is the ratio of the corresponding inverse infection rate from Table 2 to the household IFR (Table 6's second column).

Table 6's first scenario is the safest scenario in which the transmission rate found in the North Carolina study is rescaled to Vermont, which is the state with the lowest positivity rate in fall 2020. In that scenario, the number of in-person teacher-years per fatality among teachers and spouses ranges from about 45,583 for an elderly teacher living with another elderly person to about 33 million for a young teacher living without any other adult. For all ages and living arrangements, the first scenario is safer than the average occupational risk before the pandemic (Table 4). The second scenario is the "middle" estimate that takes the North Carolina study with a (slight) rescaling to average US positivity rates. ${ }^{26}$ Unless

\footnotetext{
${ }^{25}$ Children living with teachers are ignored in these calculations because their fatality rates are so close to zero. Note that the first column of Table 1 is the product of the first two columns of Table 6 .

${ }^{26}$ Recall from Table 2 that, adjusted for positivity rates, the in-school transmission rate in North Carolina was somewhat greater than both England and Wisconsin. In this sense, building the "middle" scenario on North Carolina is somewhat conservative.
} 


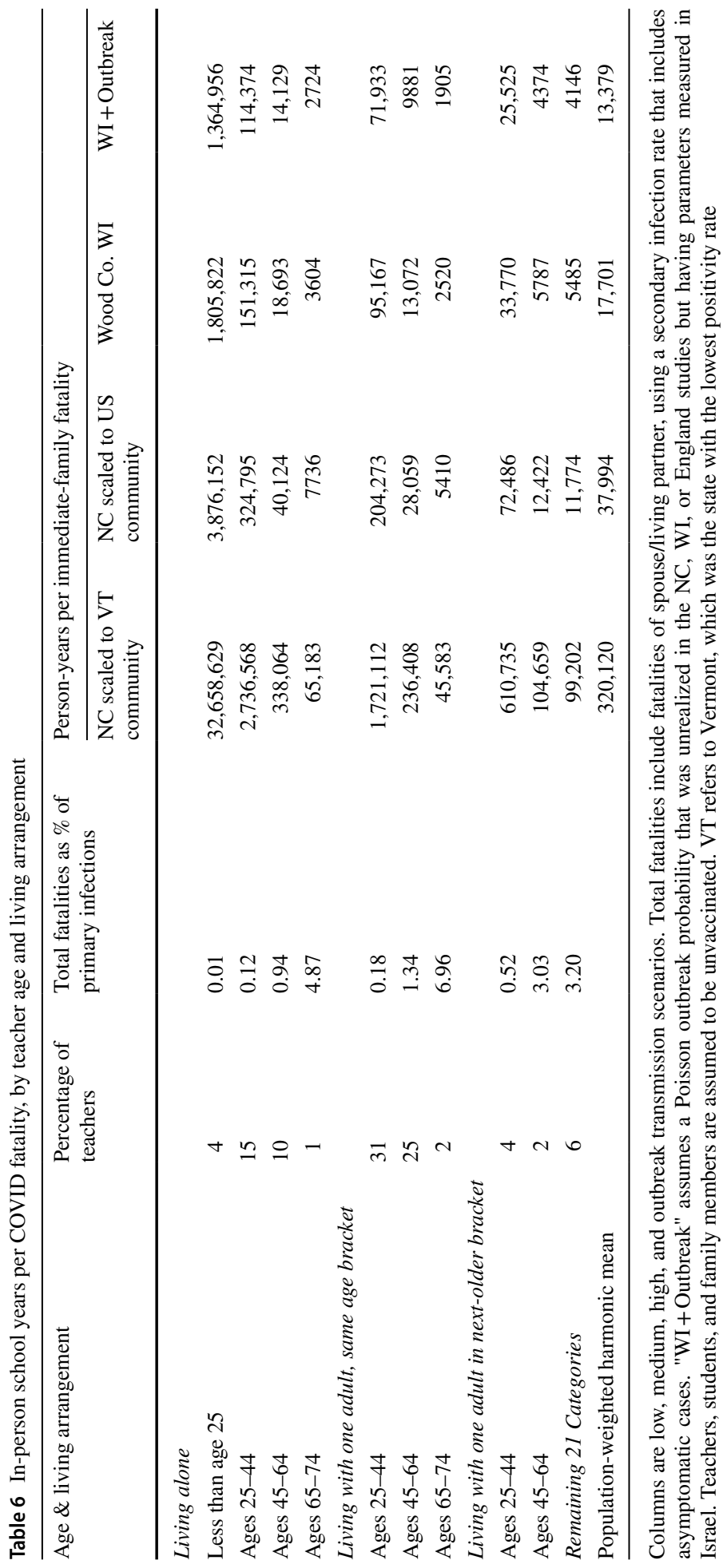




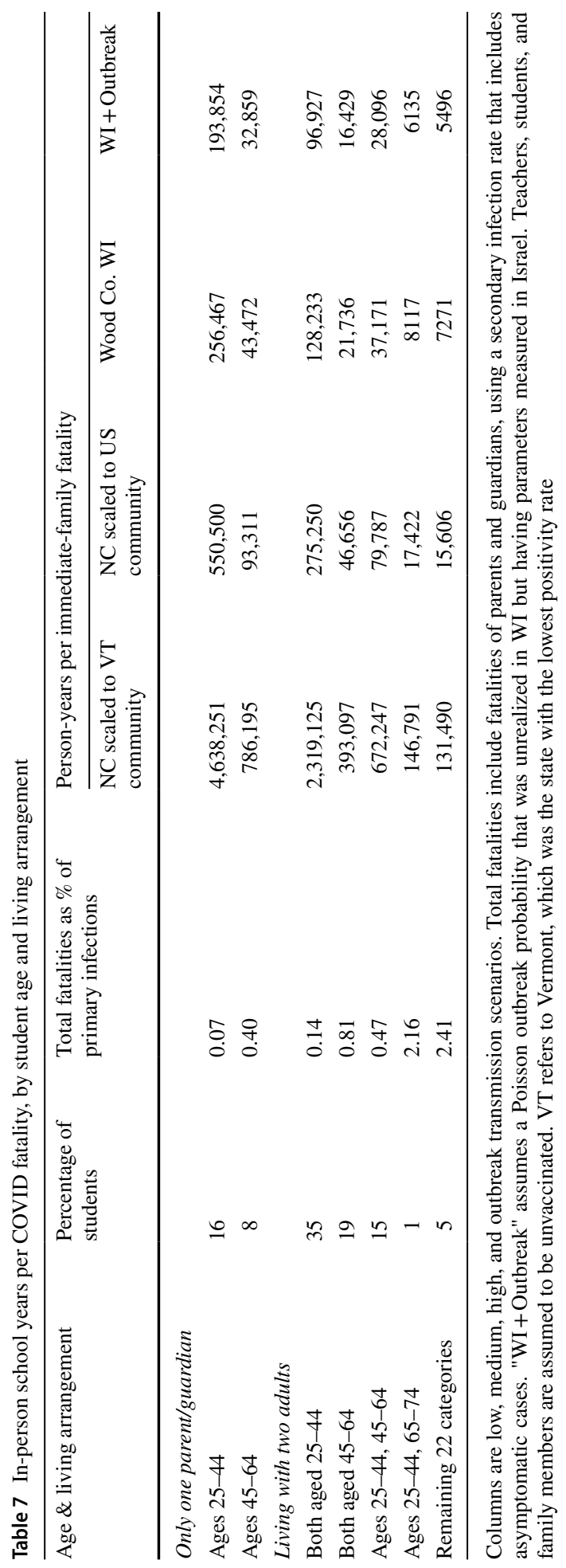


an elderly person is involved, that scenario shows fatality risks that also are similar to or less than the average pre-pandemic occupational risk.

The two relatively dangerous scenarios are derived from the Woods County, Wisconsin study without any adjustment to US positivity rates. The county's positivity rate during the study was more than triple the US average and exceeded the rate in any single US state. The unadjusted infection rate in Wood County schools was the highest of the three studies (recall Table 2). The final scenario adds the unrealized possibility of an outbreak in a school that is extensive enough to close the school. Still, even for the elderly teacher with an elderly spouse, the annualized risk is about 1/1905, like that of an aircraft pilot. On a daily basis, the risk is similar to driving in a car (alone) for 500 miles.

Table 7 shows the results for the adults living with students. It is arranged as Table 6, with rows showing ages and living arrangements and columns showing transmission scenarios. Fatality risks would be lower (more person years per fatality) in both tables-especially Table 7-to the extent that Grijalva et al. (2020) overestimate the household transmission rate, as suggested by the studies reviewed in Madewell et al. (2020).

Table 1's final three columns show the expected national number of fatalities owing to school-acquired COVID that would occur in the families of students and teachers with full in-person schooling. The totals are the product of the corresponding fatality rates shown in Tables 6 or 7 and the aggregate number of person-days in school during a normal school year. Although student families have somewhat lower fatality rates than teacher families, student families experience more total fatalities because student families are more numerous. National total COVID fatalities are not zero, but still less than automobile fatalities except in the highest-positivity scenario.

The bottom of Table 1 also shows how a year of COVID fatalities experienced by students, teachers, and their families are composed between school-acquired versus acquired outside school. ${ }^{27}$ The total of the two is 43,697 in the middle scenario, which I obtain by reweighting the 459,480 occurring nationally between February 1, 2020, and January 31, 2021, to reflect the number and age distribution of teacher and teacher families as opposed to the national age distribution. The school-acquired total is from the rows above.

Table 8 uses a $\$ 10$ million value of a statistical life (VSL) to convert the unvaccinatedteacher risks in Table 6 into dollars per day; divide by about seven hours per day to obtain hourly compensating differentials. ${ }^{28}$ The risk being priced here includes the risk of bringing a COVID-19 infection from school to home, where an unvaccinated family member becomes infected and dies, relative to an alternative with exactly zero infection risk. The compensating differences range from less than a penny per day for a young teacher living alone in a low-prevalence community to $\$ 29$ per day for an elderly teacher living with an unvaccinated elderly adult in a high-prevalence community. The compensating differentials are less than a dollar a day for the modal teacher category (aged 25-44 living with an unvaccinated adult in that age bracket).

\footnotetext{
27 As noted previously, a student infection occurring at school that is taken home and transmitted to a parent counts as "school acquired".

28 According to Kniesner and Viscusi (2019), \$10 million is in the middle of the range of estimates of the US VSL. Readers readily may apply alternative VSL values by rescaling Table 8 proportionally. The robust conclusion is that the in-person compensating differential is often just pennies per day, which is an opportunity cost dwarfed by the more familiar opportunity costs of schooling.
} 


\section{Conclusions}

This paper assembles data from several different sources that apply various methods. The data include in-school transmission rates from communities and time frames with community prevalence rates that vary by almost two orders of magnitude, age-specific prevalence from the Centers for Disease Control and Prevention (CDC), time-specific and region-specific positivity rates from the Department of Health and Human Services, and prevalence rates specific to in-person school populations obtained from Emily Oster's COVIDSchoolDashboard. The accounting framework provided in this paper shows how closely the various data fit together and support common conclusions.

\subsection{Assessment of in-person schooling during 2020}

Students and teachers at in-person schools during 2020 were about 20 times more likely to be infected outside school than in school. ${ }^{29}$ According to the studies, an important reason that acquiring an infection at school is rare is that fewer than one out of 200 students and staff test positive for COVID-19 after making close contact at school (e.g., share a class) with an infectious person. Within-household transmission rates are far higher. Relative to in-home rates, in-school infection rates are reduced by another order of magnitude because infectious students and staff tend to stay out of school. The two disease-transmission advantages of schools overwhelm their disadvantage, which is that more close contacts potentially occur in school than in the family. That observation raises the serious questions, unanswered in this paper, of (1) whether sending uninfected students and staff home for remote learning raises their probability of COVID-19 infection and death, which would be the opposite of what school closings were intended to achieve and (2) why the obvious child-development, family, and psychological benefits of in-person schooling were surrendered so widely in the United States throughout the 2020-2021 school year. ${ }^{30}$

The chance of acquiring COVID-19 in school appears to be proportional to COVID19 prevalence in the surrounding community, at least with school-prevention efforts held approximately constant. Even in high-prevalence areas by the standards of fall 2020, the expected number of fatalities in a two-adult elderly unvaccinated household is about the same whether one of those adults spent the day driving a car alone or teaching school in person during the pandemic. The fatality risks often are orders of magnitude less for teachers of different ages, living arrangements, or community prevalence. Translated into compensating differentials relative to exactly zero risk, the fatality risk of in-person teaching ranges from less than a penny per day for a young teacher living alone in a low-prevalence community to \$29 per day for an elderly teacher living with an unvaccinated elderly adult in a high-prevalence community. The compensating differentials are less than a dollar a day for the modal teacher category (aged 25-44 living with an unvaccinated adult in that age bracket). To put it another way, the fatality risk to self and living partners, which may

\footnotetext{
29 The primary- and secondary-school rates herein may be less than college rates not only because college students are older but because colleges provide both classrooms and living quarters. However, at least some college dorms drove infection rates an order of magnitude below those in surrounding communities (Mulligan, 2021b).

30 Assuming that learning occurs remotely at half the rate that it does in person, Mulligan (2021a) estimates that the pupil human-capital loss from remote learning is $\$ 666$ per teacher per day as compared to health benefits (if any) that are less than $\$ 30$ per day (Table 8 of this paper).
} 
Table 8 Estimated in-person compensating differences

\begin{tabular}{|c|c|c|c|c|c|}
\hline \multirow[t]{2}{*}{ Age \& living arrangement } & \multirow{2}{*}{$\begin{array}{l}\text { Percentage } \\
\text { of teachers }\end{array}$} & \multicolumn{4}{|c|}{ In-person premium, \$/teacher/day } \\
\hline & & $\begin{array}{l}\text { NC scaled to } \\
\text { VT commu- } \\
\text { nity }\end{array}$ & $\begin{array}{l}\text { NC scaled to } \\
\text { US commu- } \\
\text { nity }\end{array}$ & Wood Co. WI & WI + Outbreak \\
\hline \multicolumn{6}{|l|}{ Living alone } \\
\hline Less than age 25 & 4 & 0.00 & 0.01 & 0.03 & 0.04 \\
\hline Ages $25-44$ & 15 & 0.02 & 0.17 & 0.37 & 0.49 \\
\hline Ages 45-64 & 10 & 0.16 & 1.38 & 2.97 & 3.93 \\
\hline Ages $65-74$ & 1 & 0.85 & 7.18 & 15.41 & 20.39 \\
\hline \multicolumn{6}{|c|}{ Living with one adult, same age bracket } \\
\hline Ages $25-44$ & 31 & 0.03 & 0.27 & 0.58 & 0.77 \\
\hline Ages 45-64 & 25 & 0.23 & 1.98 & 4.25 & 5.62 \\
\hline Ages $65-74$ & 2 & 1.22 & 10.27 & 22.04 & 29.16 \\
\hline \multicolumn{6}{|c|}{ Living with one adult in next-older bracket } \\
\hline Ages 25-44 & 4 & 0.09 & 0.77 & 1.65 & 2.18 \\
\hline Ages 45-64 & 2 & 0.53 & 4.47 & 9.60 & 12.70 \\
\hline Remaining 22 categories & 6 & 0.56 & 4.72 & 10.13 & 13.40 \\
\hline
\end{tabular}

These are compensating differences, relative to a zero-risk alternative, for unvaccinated teachers based on Table 6 and a VSL of $\$ 10$ million. Columns are low, medium, high, and outbreak transmission scenarios. VT refers to Vermont, which was the state with the lowest positivity rate

include an elderly person, for one day taught in-person by the average nonelderly teacher was much like the risk of driving 18 miles alone in a car. For the modal teacher, the equivalent is five miles. Regardless of the magnitude of the health burden of school-acquired COVID-19, more of it is borne by the families of students than by teachers and their families.

Under the pandemic conditions that prevailed in the United States during 2020, my point estimate is about 37,994 teacher-years (1.4 million teacher-weeks) of unvaccinated in-person schooling for each fatality of a teacher or spouse from an infection that the teacher acquired in school. ${ }^{31}$ Because 1.4 million teacher weeks are associated with 21 million student weeks, 22 million people would—without a more targeted approach-have to be removed from in-person schooling for a week (and transferred to a zero-infection environment) to prevent a single fatality of a teacher or his/her spouse. As shown in the "Appendix", 22 million people distanced six feet apart could form a line that is almost 28,000 miles long, which is more than enough to encompass the entire Earth's equator. The risk of fatality from school-acquired COVID-19 is nonzero but, like some more familiar risks, small enough to significantly challenge comprehension. ${ }^{32}$

\footnotetext{
31 The 37,994 teacher-years refer to the population-weighted harmonic mean of Table 6's rescaled North Carolina column. The risk would be $34 \%$ lower if the non-elderly, who represent $95 \%$ of the workforce, did all of the teaching during the pandemic.

${ }^{32}$ For some of the papers on the accuracy of consumer risk assessments, see Kahneman and Tversky (1979), Fischhoff et al. (1981), Viscusi (1985) and Magat et al. (1988). One emerging theme is that people overestimate small risks when the risks are not part of their consumption specialty or profession, as with
} 
Although infection rates for school-age children are below adult rates, CDC data still show them to be substantial. ${ }^{33}$ I also assume that virus transmission from infected children to parents is likely. Nevertheless, I find the private health costs of in-person schooling to be low-some would say trivial-largely because (1) per capita COVID-19 deaths are few among non-elderly people and (2) schools have proven effective enough at screening out infected students and staff and achieving low secondary attack rates so as to significantly offset their disadvantage in terms of number of on-site close contacts. To an order of magnitude, item (2) puts hourly infection rates in school comparable to hourly rates outside of school. Regarding item (1), among all 280 million non-elderly people in the United States between March 1, 2020, and February 28, 2021, less than $0.001 \%$ died weekly from COVID-19. That is less risk than driving, or riding as a passenger, in an automobile for 1100 miles, which would not normally be viewed as an especially dangerous activity for a week or an activity whose cost primarily was mortality risk.

Even holding constant infection rates in the surrounding community, in-school COVID transmission rates (item (2) above) vary across schools and evolve over time. In-person schooling therefore has an option value in that it begins to reveal situation-specific inschool transmission rates. Situations with intolerably high transmission rates can be terminated with a return to remote learning. In contrast, remote learning by itself does not reveal which schools would have acceptably low transmission rates.

\subsection{Implications for other industries and time frames}

These data also undermine the implicit public-health assumption that students and staff sent home from school voluntarily will go into solitary confinement where they will not be infected or infect others. The low infection rates in schools compared to the wider community or even households may not be a mere quirk of epidemiology. At least since Coase (1937), Buchanan and Tullock (1962) and Alchian and Demsetz (1972), economists have suggested that certain local externalities are alleviated more effectively by voluntary cooperation within firms, clubs, schools, and other institutions, than they are either by government or by a set of individuals that are not part of any voluntary organization. ${ }^{34}$ Predating the pandemic, the existence and survival of voluntary organizations perhaps reveal that they manage local externalities and provide local public goods to members well enough that individuals could justify submitting to the constraints that membership requires. Mandating the closure of schools and businesses idles organizational capital that had passed a market test (Mulligan, 2021a; Mulligan et al., 2020). From an economic perspective, it is less surprising that schools and other workplaces would be places unlikely to spread COVID-19 from one person to another even though a workplace normally contains many more people than any one household does and historically may have contributed to the spread of less fatal contagious respiratory illnesses (Mulligan, 2021b).

The fall 2021 school term will proceed under different disease conditions, which can be projected by considering the combined effect of teacher vaccinations, community

\footnotetext{
Footnote 32 (continued)

nonsmoker overestimates of smoking risk (Viscusi, 1990) or occasional Israeli bus users' overestimates of the frequency of terrorist incidents (Becker and Rubinstein, 2011).

33 See also Hyde (2020).

34 Unlike, say, carbon emissions, infectious diseases are local externalities because the disease is transmitted in geographic proximity. See also Mitchell (1912), Zinberg (2021) and Leeson and Rouanet (2021).
} 
prevalence, and other components of school prevention. Teachers will have had almost a year to receive COVID-19 vaccines, which (depending on the virus variant) have been about $90 \%$ effective in preventing disease (Institute for Health Metrics \& Evaluation, 2021), which by itself reduces teacher fatalities by a factor of ten. Prevalence will be lower; by the first week of June 2021, cases per capita already were below their level of fall 2020 by a factor of 6.4. On the other hand, under these conditions schools will have less incentive to maintain other costly prevention efforts such as screening and cancelation of extracurricular activities. Eliminating all screening could by itself increase transmission by a factor of up to three (see the "Appendix"). Even if relaxing the other prevention efforts increased the other components of the in-school daily secondary attack rate by a factor of ten-something like the difference between Italy and Wood County, Wisconsin-the fatality cost of each day of in-person teaching during the 2021-2022 school year would still be less than half of what it was during 2020, which itself was both dwarfed by the other costs of schooling and small enough to challenge comprehension.

\section{Appendix: Attack rates and infection rates in school and at home}

The studies utilized in the main text measure school-acquired infection rates, defined as infections acquired in school for each person day that a student or staff is present in school. The denominator includes person days in which none of the students or staff were infected. CDC data show that, for example, only one in 6000 persons aged 5-17 were infected on the average day during the fall 2020 term. ${ }^{35}$ Although infected people may be infectious for multiple days, that observation shows why most classes would have no infections present on any given day even if students were selected randomly from the general population aged 5-17. Moreover, school protocols such as quarantine based on symptoms or family cases are designed to disproportionately sample in-school attendance from the 5999 out of 6000 who were not infected.

A daily attack rate is the probability of acquiring an infection in school for each person day that a student or staff has close contact at school. ${ }^{36}$ The school-acquired infection and attack rates are related according to ${ }^{37}$ :

$$
\begin{aligned}
(\text { school infection rate })= & (\text { new daily infection rate in the population }) \\
& *(\text { infectious days in school per infection }) \\
& *(\text { close contacts per infected }) *(\text { daily school attack rate })
\end{aligned}
$$

The first term on the RHS is outside the school. The second term can be considered to be matters of biology (how long an infection lasts) and school policy (how long an infected person is permitted in the school). If nothing else, even open schools are closed on weekends. That is, a 14-day infectious period translates to at most 10 days infectious in school for each infected student or teacher. School quarantine rules are designed to reduce the second term further toward zero. The third term also is a function of school policy, such as

\footnotetext{
35 For persons age, say, 30-49, one in 2700 were infected on a given day.

36 Infection and attack rates are sometimes defined differently than I define them here. For my purposes, the relevant definition is from the empirical studies of in-school transmission.

37 The formula infinitesimally exaggerates the infection rate because it assumes that a person could be infected twice on the same day. Algebraically, it approximates $(1-p) p$ with the infection rate $p$.
} 
the class size, whether students switch classes during the day, and whether large groups use shared facilities during the day. The daily attack rate also may be a function of school policies such as distancing and mask use.

The product of the final two terms is the in-school daily reproduction rate because it is the daily number of secondary cases acquired in the school from each infected student or staff that is present that day. ${ }^{38}$ The reproduction rate is more easily compared across studies that have different definitions of a close contact but similar definitions of a secondary case. ${ }^{39}$ On the other hand, the decomposition is useful for determining whether schools had large numbers of close contacts during the pandemic, as they did before (Mossong et al., 2008).

The purpose of this appendix is to examine daily attack rates measured in Australia by Macartney et al. (2020) and relate them to the infection-rate studies cited in Sect. 4.1. The study defined a close contact as "children or staff with face-to-face contact for at least $15 \mathrm{~min}$, or who shared a closed indoor space for at least $40 \mathrm{~min}$ (generally the same class or lesson, typically consisting of 20-30 students)" (ibid., p. 809). They measured an average of 56.3 close contacts accrued over an average of 3.4 school days for each primary case. Two cases were found among 3265 close-contact-days, which is a daily attack rate of $0.06 \%$. The last three of Eq. (2)'s terms are, in this study, $11.8 \%$.

The study was conducted in Australia between March 5 and April 9, 2020, when schools were open primarily for the children of essential workers. That place and time are not representative of the US during fall 2020 in terms of Eq. (2)'s first term. However, Eq. (2)'s first - or third or fourth — term can be calculated from US data instead to estimate a schoolacquired infection rate for the United States under the assumption that the other terms are the same as in the Australian study. Conversely, US values for the third or fourth term could be inferred under the assumption that Australia and the United States have the same attack rate.

Table 9 shows how the attack-rate studies can be reconciled with the infection-rate studies. Each panel's five rows correspond to one of the five terms from Eq. (2). The Australia column has no measured infection rate, but the second panel uses the formula $E=C D /(A B)$ by taking row D as the US average for fall 2020. Conversely, an inverse attack rate (row C) could be estimated for England, North Carolina, and Wisconsin by assuming that they share rows A and B with Australia. The results (not shown in the table) would range from about 26 contact-years for England to about 14 contact-years for North Carolina.

As noted, for each infectious student or teacher at school, an average of 56.3 close contacts were maintained for an average of 3.4 days, although the true average is less because the 3.4 excludes zeros. ${ }^{40}$ At the measured attack rate, that is nine primary cases for every secondary case (a reproduction rate of about 1/9), whereas at home the ratio is about two primary cases for every secondary one. Presumably, infectious close contacts last longer at home, perhaps up to 14 days (also for more hours). That still leaves a residual between

\footnotetext{
38 Infectious days at school are sometime combined with the daily attack rate. I use the decomposition to highlight where school policies might offset the large number of close contacts in the school context.

39 The definition of close contact cancels in the multiplication if it is broad enough to encompass all secondary infections.

40 If index students were infectious for a full 14 days and were present in school for all 10 of those weekdays, then all else the same, the (cumulative) in-school reproduction rate in Australia would have been about three $(=10 / 3.4)$ times greater.
} 


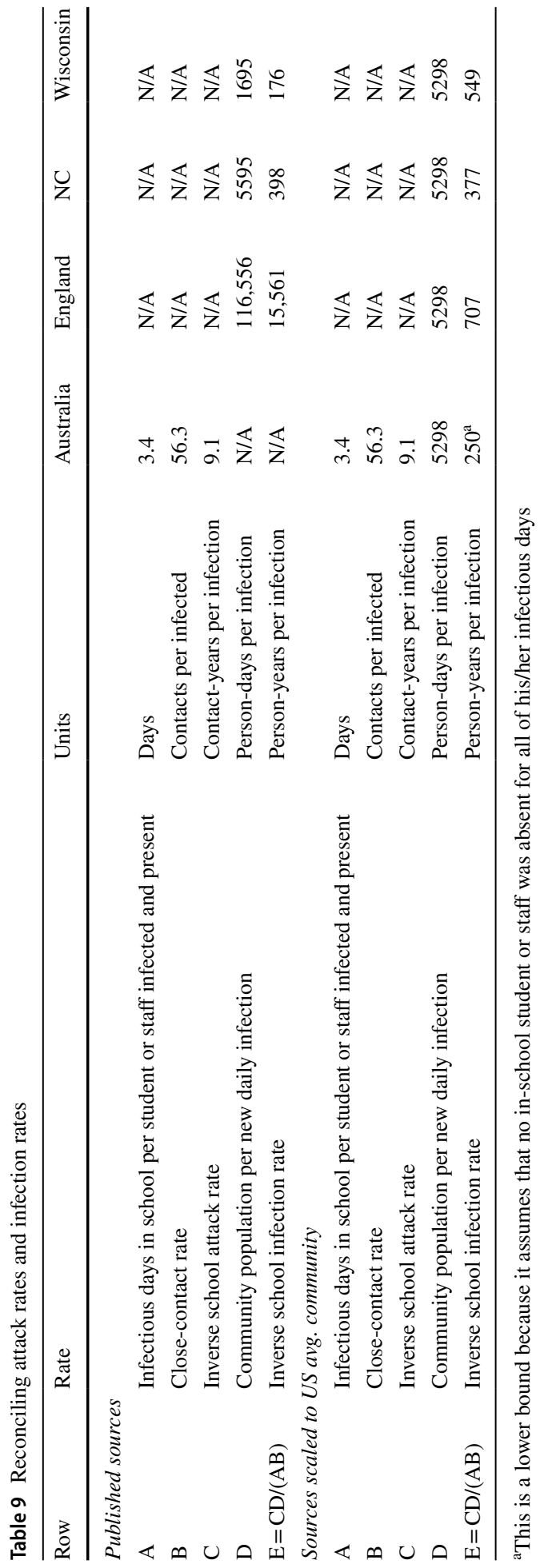


Table 10 Reconciling in-school reproduction rates with infection-source shares. Sources Falk et al. (2021), Zimmerman et al. (2021), Doyle et al. (2021), Macartney et al. (2020), Danis et al. (2020), Heavey et al. (2020), and Larosa et al. (2020), respectively

\begin{tabular}{|c|c|c|c|c|c|c|c|}
\hline \multirow[t]{2}{*}{ Location } & \multirow[t]{2}{*}{ Contacted set } & \multicolumn{2}{|c|}{$\begin{array}{l}\text { School-acquired cases } \\
\text { as a ratio to commu- } \\
\text { nity-acquired }\end{array}$} & \multirow[t]{2}{*}{ SAR } & \multirow[t]{2}{*}{$\begin{array}{l}\text { Avg no. } \\
\text { of con- } \\
\text { tacts }\end{array}$} & \multicolumn{2}{|c|}{ In-school reproduction rate } \\
\hline & & Measured & $\begin{array}{l}\text { Upper bbd } \\
\text { from SAR }\end{array}$ & & & Measured & $\begin{array}{l}\text { Lower bbd from } \\
\text { infection-source }\end{array}$ \\
\hline \multicolumn{8}{|c|}{ Infection-source studies } \\
\hline Wood Co., WI & Students & 0.06 & & & & & 0.06 \\
\hline Wood Co., WI & Staff & $\mathbf{0}$ & & & & & 0 \\
\hline Wood Co., WI & Students \& Staff & 0.04 & & & & & 0.04 \\
\hline North Carolina & Students \& Staff & 0.04 & & & & & 0.04 \\
\hline Florida & Students \& Staff & 0.12 & & & & & 0.12 \\
\hline \multicolumn{8}{|c|}{ Secondary attack rate (SAR) studies } \\
\hline Australia & Students & & 0.11 & $0.1 \%$ & 86.6 & 0.11 & \\
\hline Australia & Staff & & 0.13 & $0.7 \%$ & 16.9 & 0.13 & \\
\hline Australia & Students \& Staff & & 0.12 & $0.2 \%$ & 56.3 & 0.12 & \\
\hline France & Students \& Staff & & $\mathbf{0}$ & 0 & & 0 & \\
\hline Ireland & Students \& Staff & & $\mathbf{0}$ & 0 & & 0 & \\
\hline Italy & Students & & 1.03 & $3.8 \%$ & 26.9 & 1.03 & \\
\hline Italy & Staff & & $\mathbf{0}$ & 0 & & 0 & \\
\hline Italy & Students \& Staff & & 0.79 & $3.2 \%$ & 25 & 0.79 & \\
\hline
\end{tabular}

For contact subsets, the average number of contacts is calculated as a residual. The two measures of schoolto-community acquired cases are shown in bold columns

Table 11 Translating infection frequencies to line length

\begin{tabular}{ll}
\hline Pupil-teacher ratio & 15.4 \\
Teacher-years to remote learning & 37,994 \\
Teacher-weeks to remote learning & $1,367,784$ \\
Student-weeks to remote learning & $21,063,872$ \\
Total persons to remote learning & $22,431,656$ \\
Distances in feet & \\
Between persons & 6 \\
Thickness of a person & 1 \\
Distances in miles & \\
Length of remote-learning line & 27,615 \\
Earth's equator & 24,901 \\
Length of remote-learning line & \\
Earth's equator coverage & $111 \%$ \\
\hline
\end{tabular}

attack rates in schools and homes, which might be explained by mitigation protocols used in schools but not homes.

Because the reproduction rate is the ratio of secondary cases to corresponding "index" cases brought into school from the outside, it is an upper bound on the steady-state ratio 
of school-acquired cases to all other cases that in-person students and staff experienced, which include cases never brought into school. Table 10 compares the school-acquired fractions whose numerators and denominators are measured directly in the Wisconsin and North Carolina studies, as well as a third Florida study (Doyle et al., 2021) that measures (a transformation of) the fraction, to the Australian, French, Irish, and Italian studies measuring in-school reproduction rates. ${ }^{41}$ Six of the seven "Students \& Staff" estimates are less than 0.125 , which means that less than one-ninth of the infections among in-person students and staff were acquired in school. The seventh estimate (Italy) is 0.79 , which still is less than one.

The SAR-contacts decomposition of the reproduction rates is also shown in Table 10. As expected, the average number of contacts at school is large. What is more surprising is that the secondary attack rate is low-usually less than $1 \%$-potentially enough to offset the high number of contacts.

Table 11 shows how I translated the (inverse) frequency of school-acquired infections into a line of students and teachers. My point estimate is about 38,000 teacher-years (1.4 million teacher-weeks) of in-person schooling for each fatality of a teacher or spouse from an infection that the teacher acquired in school. Because 1.4 million teacher weeks are associated with 21 million student weeks, 22 million people would-without a more targeted approach-have to be removed from in-person schooling for a week (and transferred to a zero-infection environment) to prevent a single teacher fatality. Twenty-two million people distanced six feet apart could form a line that is almost 28,000 miles long, which is long enough to encompass the entire Earth's equator and overlap itself 2700 miles.

Acknowledgements I appreciate financial support from the University of Chicago's Initiative on Enabling Choice and Competition in Healthcare, the research assistance of Alex Kahn, conversations with Kevin M. Murphy, Emily Oster, Bob Topel, Phil Kerpen and Emily Burns, and clarifications from Timothy Doyle and Professors Kanecia Zimmerman and Daniel Benjamin.

\section{References}

Alchian, A. A., \& Demsetz, H. (1972). Production, information costs, and economic organization. The American Economic Review, 62, 777-795.

Alon, T., et al. (2021). From Mancession to Shecession: Women's employment in regular and pandemic recessions. NBER working paper no. 28632.

Becker, G. S., \& Rubinstein, Y. (2011). Fear and the response to terrorism: An economic analysis. CEP discussion paper no. 1079.

Buchanan James, M., \& Tullock, G. (1962). The calculus of consent. University of Michigan Press.

Bravata, et al. (2021, April). Back to School: The effect of school visits during COVID-19 on COVID-19 transmission. NBER working paper no. 28645.

Cauchemez, S., et al. (2008). Estimating the impact of school closure on influenza transmission from Sentinel data. Nature, 452, 750-754.

Centers for Disease Control and Prevention. (2021). Demographic trends of COVID-19 cases and deaths in the US reported to CDC. Retrieved March 20, 2021, from https://covid.cdc.gov/covid-data-tracker/\# demographics.

Coase, R. (1937). The theory of the firm. Economica, 4, 386-405.

\footnotetext{
41 Also note that asymptomatic cases acquired outside school are unlikely to be measured by the Wisconsin and North Carolina studies, whereas the latter study tested at least some of the asymptomatic close school contacts. As part of their estimates of secondary attack rates, the Australian and Italian studies included asymptomatic secondary cases. The French and Irish studies found no secondary cases.
} 
Courtemanche, C. J., et al. (2021). School reopenings, mobility, and COVID-19 spread: Evidence from Texas. NBER working paper no. 28753.

Danis, Kostas, et al. (2020). Cluster of coronavirus disease 2019 (COVID-19) in the French Alps, February 2020. Clinical Infectious Diseases, 71, 825-832.

Doyle, T., et al. (2021). COVID-19 in primary and secondary school settings during the first semester of school reopening-Florida, August-December 2020. Morbidity and Mortality Weekly Report, 70, 437.

Falk, A., et al. (2021). COVID-19 cases and transmission in $17 \mathrm{~K}-12$ schools-Wood County, Wisconsin, August 31-November 29, 2020. Morbidity and Mortality Weekly Report, 70, 136.

Fischhoff, B., et al. (1981). Acceptable risk. Cambridge University Press.

Goldhaber, D., et al. (2021). To what extent does in-person schooling contribute to the spread of COVID19? Evidence from Michigan and Washington. NBER working paper no. 28455.

Grijalva, C. G., et al. (2020). Transmission of SARS-COV-2 infections in households-Tennessee and Wisconsin, April-September 2020. Morbidity and Mortality Weekly Report, 69, 1631.

Harris, D. N., Ziedan, E., \& Hassig, S. (2021). The effects of school reopenings on COVID-19 hospitalizations. National Center for Research on Education Access and Choice.

Heavey, et al. (2020). No evidence of secondary transmission of COVID-19 from children attending school in Ireland, 2020. Eurosurveillance, 25, 2000903.

Hyde, Z. (2020). COVID-19, children, and schools: Overlooked and at risk. Medical Journal of Australia, 213, 444-446.

Institute for Health Metrics and Evaluation. (2021). COVID-19 vaccine efficacy summary. Retrieved June 22, 2021, from http://www.healthdata.org/covid/covid-19-vaccine-efficacy-summary.

Ismail, S. A., et al. (2020). SARS-CoV-2 infection and transmission in educational settings: A prospective, cross-sectional analysis of infection clusters and outbreaks in England. The Lancet Infectious Diseases.

Isphording, I. E., Lipfert, M., \& Pestel, N. (2020). School re-openings after summer breaks in Germany did not increase SARS-CoV-2 Cases. Technical report, IZA Discussion Papers.

Kahneman, D., \& Tversky, A. (1979). An analysis of decision under risk. Econometrica, 47, 263-292.

Kniesner, T. J., \& Viscusi, W. K. (2019). The value of a statistical life. In Oxford research Encyclopedias: Economics and finance. Oxford University Press. https://doi.org/10.1093/acrefore/9780190625979. 013.138

Larosa, E., et al. (2020). Secondary transmission of COVID-19 in preschool and school settings in northern Italy after their reopening in September 2020: A population-based study. Eurosurveillance, 25, 2001911.

Ludvigsson, et al. (2021). Open Schools, Covid-19, and Child and Teacher Morbidity in Sweden. New England Journal of Medicine, 384, 669-671.

Leeson, P. T., \& Rouanet, L. (2021). Externality and COVID-19. Southern Economic Journal, 87, 1107-1118.

Lessler, J., et al. (2021). Household COVID-19 risk and in-person schooling. Science, 372, 1092-1097.

Macartney, K., et al. (2020). Transmission of SARS-CoV-2 in Australian educational settings: A prospective cohort study. The Lancet Child \& Adolescent Health, 4, 807-816.

Madewell, Z. J., et al. (2020). Household transmission of SARS-CoV-2: A systematic review and metaanalysis. JAMA Network Open, 3, e2031756-e2031756.

Magat, W. A., Viscusi, W. K., \& Huber, J. (1988). Consumer processing of hazard warning information. Journal of Risk and Uncertainty, 1, 201-232.

Maldonado, J. E., \& De Witte, K. (2020). The effect of school closures on standardised student test outcomes. KU Leuven Department of Economics Discussion Paper, 17.

Mitchell, W. C. (1912). The backward art of spending money. The American Economic Review, 2(2), $269-281$.

Mossong, J., et al. (2008). Social contacts and mixing patterns relevant to the spread of infectious diseases. PLoS Medicine, 5, e74.

Mulligan, C. B. (2021a). Economic activity and the value of medical innovation during a pandemic. Journal of Benefit Cost Analysis.

Mulligan, C. B. (2021b). The backward art of slowing the spread? Congregation efficiencies during COVID19. NBER working paper no. 28737.

Mulligan, C. B., Murphy, K. M., \& Topel, R. H. (2020). Some basic economics of COVID-19 policy. Chicago Booth Review.

National Center for Education Statistics. (2020). 2019 Digest of Education Statistics. Retrieved June 7, 2021, from https://nces.ed.gov/programs/digest/2019menu_tables.asp.

National Safety Council. (2020). Motor vehicle deaths, injuries, and number of crashes by type of crash, United States, 2019. Retrieved June 23, 2021, from https://injuryfacts.nsc.org/motor-vehicle/overview/ type-of-crash/. Accessed 23 June 2021. 
Oster, E. (2020a). What parents need to know about school coronavirus case data. New York Times. Retrieved March 22, 2021, from https:/www.nytimes.com/2020/09/28/opinion/schools-coronavirus. html. Accessed 22 March 2021.

Oster, E. (2020b). Schools aren't super-spreaders. The Atlantic. Retrieved October 9, 2020, from https:// www.nytimes.com/2020/09/28/opinion/schools-coronavirus.html.

Oster, E., et al. (2021). COVID-19 mitigation practices and COVID-19 rates in schools: Report on data from Florida, New York and Massachusetts. medRxiv.

Philipson, T. (2000). Economic epidemiology and infectious diseases. Handbook of Health Economics, 1, 1761-1799.

Pittsville School District. (2020). August 10, 2020 fall reopening plan. Retrieved March 20, 2021, from https://www.pittsville.k12.wi.ushttps://www.pittsville.k12.wi.us/20202021SchoolBoardMeetings/ 08102020Meeting/August\%2010\%202020\%20Fall\%20Opening\%20Plan1.pdf.

Port Edwards School District. (2020a). August-September 2020 newsletter. Retrieved March 20, 2021, from http://www.pesd.k12.wi.us/wp-content/uploads/2020/08/2020-AugustSeptember-Newsletter-1.pdf.

Port Edwards School District. (2020b). Letter to elementary parents from pupil services director. Retrieved March 20, 2021, from http://www.pesd.k12.wi.us/wp-content/uploads/2020/08/Elem-2020.pdf.

Savage, I. (2013). Comparing the fatality risks in United States transportation across modes and over time. Research in Transportation Economics, 43, 9-22.

School District of Auburndale. (2020). Regular board meeting Wednesday August 19, 2020. Retrieved March 20, 2021, from https://www.aubschools.com/cms/lib/WI02215817/Centricity/Domain/27/ Minutes\%208_19_2020.pdf.

School District of Marshfield. (2020). District home. Retrieved March 20, 2021, from https://www.marsh fieldschools.org.

School District of Nekoosa. (2020). Home page. Retrieved March 20, 2021, from https://www.nekoosasd. net.

Stein-Zamir, C., et al. (2020). A large COVID-19 outbreak in a high school 10 days after schools' reopening, Israel, May 2020. Eurosurveillance, 25, 2001352.

U.K. Office of Statistics Regulation. (2020). Attendance in education and early years settings during the coronavirus (COVID-19) outbreak. Retrieved March 18, 2021, from https://content.explore-educationstatistics.service.gov.uk/api/releases/e9fca3d7-4a96-4f9a-49e0-08d84a918dfb/files/56dd5ae6-f8ef4c9d-c349-08d84a9eaaad.

U.S. Bureau of Labor Statistics. (2010). Change to Hours-Based Fatality Rates in the Census of Fatal Occupational Injuries. Retrieved March 20, 2021, from https://www.bls.gov/opub/mlr/cwc/change-tohours-based-fatality-rates-in-the-census-of-fatal-occupational-injuries.pdf.

U.S. Bureau of Labor Statistics. (2020a). Number and rate of fatal work injuries, by industry sector. Retrieved June 21, 2021, from https://www.bls.gov/charts/census-of-fatal-occupational-injuries/number-and-rate-of-fatal-work-injuries-by-industry.htm.

U.S. Bureau of Labor Statistics. (2020b). National Census of Fatal Occupational Injuries in 2019. Retrieved June 16, 2021, from https://www.bls.gov/news.release/pdf/cfoi.pdf.

U.S. Bureau of Labor Statistics. (2020c). Number and rate of fatal work injuries, civilian workers, by major occupational group. Retrieved June 16, 2021, from https://www.bls.gov/charts/census-of-fatal-occup ational-injuries/number-and-rate-of-fatal-work-injuries-by-occupation.htm.

U.S. Bureau of Labor Statistics. (2020d). Fact Sheet: Police Officers 2018. Retrieved June 16, 2021, from https://www.bls.gov/iif/oshwc/cfoi/police-2018.htm.

U.S. Department of Health and Human Services. (2021). COVID-19 diagnostic laboratory testing (PCR Testing) time series. Retrieved March 20, 2021, from https://healthdata.gov/dataset/COVID-19-Diagn ostic-Laboratory-Testing-PCR-Testing/j8mb-icvb 2021.

U.S. Dept. of Transportation, National Highway Traffic Safety Administration. (2017). Quick facts 2016. Retrieved June 16, 2021, from https://crashstats.nhtsa.dot.gov/Api/Public/ViewPublication/812451.

U.S. Dept. of Transportation, National Highway Traffic Safety Administration. (2020). Overview of motor vehicle crashes in 2019. Traffic Safety Facts. Retrieved June 16, 2021, from https://crashstats.nhtsa.dot. gov/Api/Public/ViewPublication/813060.

van den Berg, P., et al. (2021). Effectiveness of 3 versus $6 \mathrm{ft}$ of physical distancing for controlling spread of coronavirus disease 2019 among primary and secondary students and staff: a retrospective, statewide cohort study. Clinical Infectious Diseases. https://doi.org/10.1093/cid/ciab230

Viscusi, W. K. (1985). A Bayesian perspective on biases in risk perception. Economics Letters, 17, $59-62$.

Viscusi, W. K. (1990). Do smokers underestimate risks? Journal of Political Economy, 98, 1253-1269.

Viscusi, W. K. (1992). Fatal tradeoffs: Public and private responsibilities for risk. Oxford University Press.

Viscusi, W. K., \& Aldy, J. E. (2003). The value of a statistical life: A critical review of market estimates throughout the world. Journal of Risk and Uncertainty, 27, 5-76. 
Vlachos, J., Hertegård, E., \& Svaleryd, H. B. (2021). The effects of school closures on SARS-CoV-2 among parents and teachers. Proceedings of the National Academy of Sciences, 118, e2020834118.

Wang, J., et al. (2021). Progression of myopia in school-aged children after COVID-19 home confinement. JAMA Ophthalmology, 139, 293-300.

Yang, W., et al. (2021). Estimating the infection-fatality risk of SARS-CoV-2 in New York City during the spring 2020 pandemic wave: A model-based analysis. The Lancet Infectious Diseases, 21, 203-212.

Zimmerman, K. O., et al. (2021). Incidence and secondary transmission of SARS-CoV-2 infections in schools. Pediatrics. 147, e2020048090.

Zinberg, J. (2021). Don't wait to reopen schools. City Journal. Retrieved January 29, 2021, from https:// www.city-journal.org/dont-wait-100-days-to-reopen-schools

Publisher's Note Springer Nature remains neutral with regard to jurisdictional claims in published maps and institutional affiliations. 